\title{
Formação continuada com quadrinhos nas aulas de Ciências: algum problema?
}

\author{
Letícia dos Santos Carvalho \\ André Ferrer Pinto Martins \\ Universidade Federal do Rio Grande do Norte
}

\section{Resumo}

Este estudo se inscreve no âmbito da formação continuada em serviço, abarcando o ensino de ciências como área e as histórias em quadrinhos como estratégia para efetivação da proposta. Objetiva discutir os obstáculos e as possibilidades apresentadas em um processo de formação continuada em serviço de uma professora que leciona ciências naturais nos anos iniciais do ensino fundamental, que utilizou como estratégia metodológica histórias em quadrinhos da Turma da Mônica. A pesquisa se desenvolveu seguindo uma abordagem qualitativa, por meio da pesquisa-ação. 0 estudo evidencia a contribuição da formação continuada com enfoque reflexivo para o redimensionamento da prática pedagógica.

Palavras-chave: Formação continuada em serviço. Ensino de ciências. Histórias em quadrinhos. 


\section{Continuing education making use of comic books in science classes: Any problem?}

The present study is within the scope of the continuing education of professionals, in the area of science teaching, and using comic books as a strategy. Its main goal is to discuss the obstacles and possibilities presented in a process of continuing education of a primary school science teacher, using "Monica's Gang" Comics as a methodological strategy. Qualitative research was conducted, using the action research methodology. The study makes evident the contribution of continuing education towards the resizing of pedagogical issues.

Keywords: Continuing education. Science teaching. Comic books.

\section{Formación continuada con tebeos en las clases de ciencias: ¿algún problema?}

Este estudio se inscribe en el marco de la formación continua, incluyendo la enseñanza de las ciencias como un área y los tebeos como una estrategia para la implementación de la propuesta. Tiene como objetivo discutir los obstáculos y oportunidades que se presentan en un proceso de formación continua en el servicio de un profesor que enseña ciencias naturales en los primeros años de escuela primaria, que utiliza como estrategia metodológica los tebeos de Mónica y su pandilla. La encuesta fue desarrollada siguiendo un enfoque cualitativo, a través de la investigación en acción. El estudio destaca la contribución de la formación continuada con un enfoque reflexivo para el cambio de la práctica pedagógica.

Palabras-clave: formación continua en servicio. Enseñanza de la Ciencia. Tebeos. 


\section{Desvelando o contexto da pesquisa e situando a problemática}

0 presente artigo situa-se sob duas perspectivas: a do uso de histórias em quadrinhos (HQ) como estratégia didática e a da formação de professores para o ensino de ciências nos anos iniciais do ensino fundamental.

Hoje em dia, já se percebe que as HQs possuem potencialidade pedagógica especial e podem dar suporte a novas modalidades educativas, podendo ser utilizadas em todas as disciplinas (Vergueiro; Ramos, 2009). Atualmente, nas investigações das áreas de educação e de ensino de ciências, pela crescente percepção das potencialidades didáticas dos quadrinhos para o ensino, estudos têm tornado a discussão menos incipiente (Pizarro, 2009; Gonçalvez; Machado, 2005; Kamel, 2006). Porém, pela revisão da literatura, são percebidos poucos espaços de formação docente nos quais os professores façam uso dos quadrinhos, mesmo após estes começarem a fazer parte do Programa Nacional Biblioteca na Escola (PNBE). (Vergueiro; Ramos, 2009)

Nesse sentido, o presente artigo busca fomentar a discussão acerca da ação didática dos professores no tocante à elaboração de estratégias inovadoras e contextualizadas com as vivências dos aprendizes. Nesse trajeto elegemos, no âmbito da abordagem qualitativa, a pesquisa-ação como o procedimento metodológico com o qual nosso estudo encontrou mais similaridades. Assim, buscamos os instrumentos e as estratégias que melhor pudessem desvelar o nosso objeto de estudo. A pesquisa realizada, que envolveu a formação continuada em serviço de três professoras, será aqui descrita através de um recorte focalizando o processo formativo de uma delas.

Organizamos o trabalho em seções. Na primeira, apresentamos a base teórica que será o pano de fundo de toda a discussão: a formação continuada e suas diversas ramificações, com ênfase no enfoque reflexivo sobre a prática, que é o que subsidia o nosso estudo. Em seguida, traçamos as estratégias metodológicas do estudo em questão para então desvelar as especificidades da educadora que será alvo de nossa análise. A escolha das histórias em quadrinhos da Turma da Mônica deveu-se ao fato de encontrarmos histórias comercializadas que apresentam conteúdos conceituais da área das ciências naturais, como também pelo fato de sua leitura ser a mais utilizada pelas crianças dessa faixa etária, segundo dados de pesquisa (Amarilha, 1994; Higuchi, 1997). Finalizamos realizando a interlocução entre o arcabouço teórico e a formação continuada em serviço, tecendo comentários conclusivos que sinalizam para as dificuldades e possibilidades do processo formativo, fomentando a discussão acerca do enfoque reflexivo sobre a prática.

\section{Formação continuada em serviço: Como? Para quê?}

Em educação, mais especificamente na formação de professores, não se pode falar em uma única vertente, mas na sua multiplicidade. Uma destas, defendida por Imbernón 
(2009), é que o professor seja formado para a incerteza, esta proveniente da complexidade do fazer docente. Já Contreras (2002) defende a autonomia dos professores como promotora da emancipação social e pessoal. Freire $(1996,2002,2005,2006,2008)$ nos incita a ter o diálogo como uma prática de liberdade, sendo a dialogicidade uma forma de superação da educação bancária (como também da formação bancária), percebendo o outro como sujeito cognoscente. Já Schön (2000) difunde a ideia da necessidade da reflexão do profissional (da educação). Giroux (1990) atenta para a emergência de se conceber o professor como intelectual transformador, e não mais um reprodutor das ideologias dominantes. Para isso, Pimenta (2008) sinaliza que o educador deve ser não apenas reflexivo, mas crítico, estando ancorado nas teorias da educação para com elas ter possibilidade de dialogar e, assim, ter a possibilidade de tecer relações entre teoria e prática, de forma imbricada, sem dicotomias. São ideias pertinentes para o âmbito educacional, todas sendo fruto de estudos que, embora distintos em suas vertentes teóricas, têm como eixo fundador a necessidade de se lançar um olhar mais cuidadoso para a educação e o educador.

Consideramos que a formação docente deve ocorrer em seu lócus principal: a escola. E esta, por sua vez, não deve se constituir apenas em uma estrutura física na qual o professor leciona, mas sim em uma escola reflexiva (Alarcão, 2001), aberta ao diálogo, que pense em si, na sua missão social; um organismo vivo, no qual se desenvolvem relações interpessoais em que há reciprocidade e dialeticidade. Nesse espaço, o professor deve buscar as respostas para as suas inquietações, de forma coletiva.

Pelo dito anteriormente, nos questionamos: que tipo de formação os professores têm recebido? Segundo Pérez Gómez (1998), existem quatro perspectivas básicas: a acadêmica, a técnica, a prática e a voltada para a reconstrução social.

As ramificações das quatro perspectivas apontadas são visualizadas a partir do organograma a seguir:

Figura 1: Perspectivas ideológicas de formação docente eseus desdobramentos.

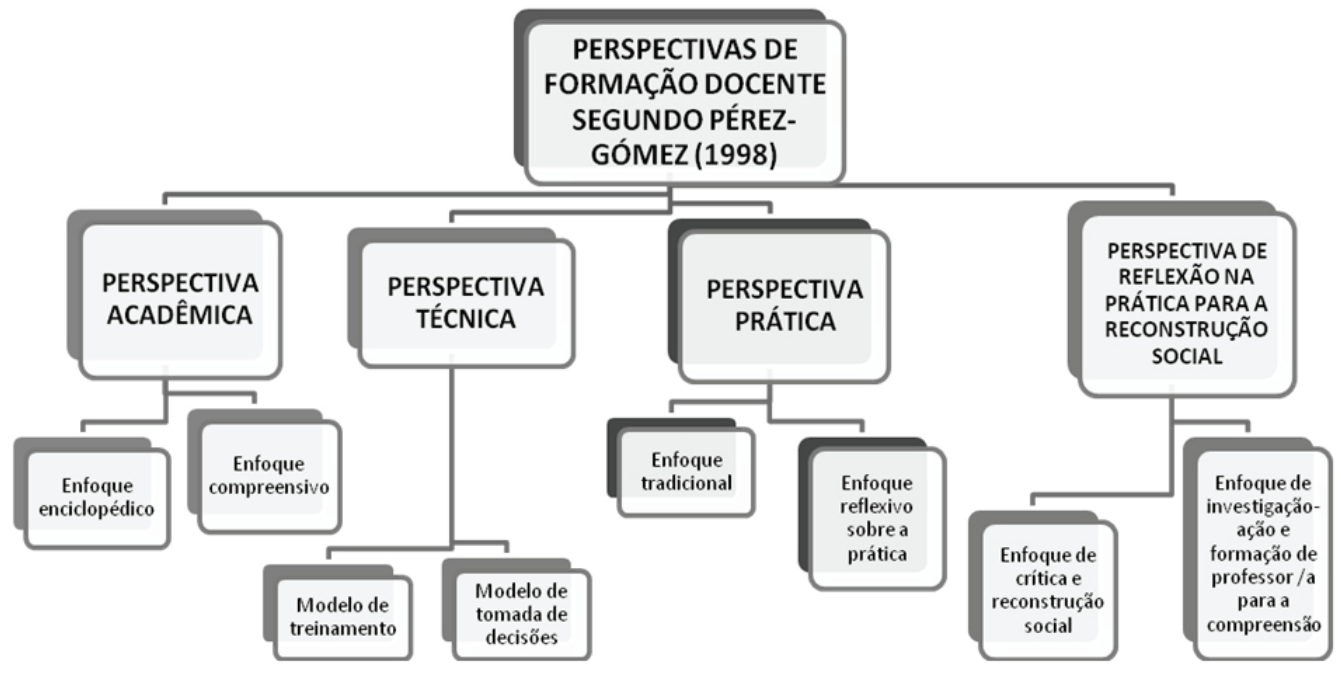

Fonte: Figura elaborada pelos autores para fins deste estudo. 
A perspectiva acadêmica concebe o processo de aprendizagem como um contínuo agregar de informações. No enfoque enciclopédico, como o próprio nome já sugere, sinaliza-se que, quanto mais conhecimento acadêmico o professor tiver, melhor executará a sua atividade docente. Já no enfoque compreensivo, o professor não é visto como esse dono do saber, mas como um intelectual que medeia a relação entre o aluno e a cultura elaborada. Já a perspectiva técnica, voltada para o que Schön (2000) denomina de "racionalidade técnica", está ligada ao uso do método científico, buscando aplicar rigorosamente o conhecimento teórico/acadêmico. Esse modelo de formação dissocia completamente a teoria da prática e não abre espaço para uma reflexão das atitudes. 0 autor sinaliza que podemos desmembrá-la em dois modelos: o de treinamento e o de tomada de decisões. 0 de treinamento é pautado nas "competências" específicas e habilidades de intervenção, seguindo um modelo empresarial para se atingir os objetivos desejados. No modelo de tomada de decisões, percebe-se um viés mais cognitivo, porém o padrão direcionado para a eficácia ainda é o pano de fundo. Na perspectiva prática, a formação está intimamente ligada à aprendizagem da prática, pela prática e para a prática, pois reconhece os espaços singulares de intervenção da docência. Tal vertente foi subdividida em dois enfoques: o tradicional e o enfoque reflexivo sobre a prática. No enfoque tradicional, o ensino é concebido como uma atividade artesanal gerada pelo conhecimento tácito. Já no enfoque reflexivo sobre a prática, vertente essa que foi se configurando visando dar uma resposta à racionalidade técnica, o professor é percebido como profissional crítico, reflexivo e pesquisador, profissional com suas particularidades. Esse ponto de vista põe em cheque o caráter reprodutor, asséptico e acultural da vertente da racionalidade técnica.

Sabemos que a simples formação sem uma postura crítica não tem o poder de transformar o fazer docente em um ato reflexivo, o que requer o pensar sobre o seu sentido formativo, como aponta Schön (2000, p.32): “Podemos refletir sobre a ação pensando retrospectivamente sobre o que fizemos, de modo a descobrir como o nosso conhecer-na-ação pode ter contribuído para um resultado inesperado".

Porém, esse processo de reflexão deve ser bem compreendido. Pimenta (2008, p.22), apesar de reconhecer a relevância dos estudos de Schön (2000) para a valorização da pesquisa e da prática, levanta alguns questionamentos que nos levam a pensar na temática: "Que tipo de reflexão tem sido realizada pelos professores? As reflexões incorporam um processo de consciência das implicações sociais, econômicas e políticas da atividade de ensinar? Que condições têm os professores para refletir?". A partir do que foi questionado, Pimenta (2008) sinaliza a valorização exacerbada da reflexão individual do docente, o que tira a concepção de grupo e não o faz perceber a tessitura e as relações dialéticas que se efetivam na sala de aula, o que está em consonância 
com o pensamento de Giroux (1990), quando destaca a necessidade da compreensão teórica dos elementos que compõem a prática profissional. Essa vertente epistemológica é condição sine qua non para que o professor seja, de fato, um intelectual transformador. Tal paralelo está relacionado com a última perspectiva elencada por Pérez Gómez (1998), que é a da reflexão na prática para a construção social, na qual o professor é considerado um profissional autônomo que reflete criticamente sobre a prática cotidiana para compreender tanto as características dos processos de ensino-aprendizagem quanto do contexto em que o ensino ocorre, de modo que a sua atuação reflexiva facilite o desenvolvimento autônomo e emancipado dos que participam do processo educativo. 0 enfoque de crítica e reconstrução social enfatiza a importância do desenvolvimento da consciência social dos sujeitos, com vistas à emancipação social, tanto individual, quanto coletiva. Já no enfoque de investigação-ação e formação do professor/a para a compreensão, a prática docente é percebida como prática intelectual e autônoma, havendo a transformação da realidade pela mudança na concepção de currículo, escola e fazer docente.

Em nosso caso, o desenho da pesquisa, como também o tipo de inserção no ambiente escolar se deram na perspectiva do enfoque reflexivo sobre a prática, que será o arcabouço teórico que seguiremos no decorrer do artigo. A partir das várias referências anteriormente citadas, podemos conceber o enfoque reflexivo sobre a prática como uma proposta que tem em sua essência a emancipação e a reflexão na ação, considerando que, da ação à investigação, há o planejamento, a ação, a descrição da ação e a avaliação da ação de forma integrada, em um movimento contínuo, que pode ser representado iconograficamente por espirais cíclicas, no ato de pensar sobre a prática. De acordo com Pimenta (2006, 2008), Rosa (2004), e Tripp (2005), ao se iniciar uma pesquisa com enfoque reflexivo, como a pesquisa-ação, são geradas espirais cíclicas/autorreflexivas tanto no âmbito da pesquisa quanto nos sujeitos envolvidos no processo.

\section{Quadro teórico-metodológico}

Pensando em uma formação continuada em serviço que contemplasse tanto o ensino de Ciências, enquanto área, como as histórias em quadrinhos, como estratégia de ensino, é que desenvolvemos a pesquisa que aqui será parcialmente discutida, que se configurou como uma pesquisa-ação e se delineou em quatro momentos distintos, detalhados na Tabela 1, a seguir: 
Quadro 1: metodologia da pesquisa

\begin{tabular}{|c|c|}
\hline $1^{\circ}$ momento & $\begin{array}{l}\text { - Contato com a instituição educativa } \\
\text { - Apresentação da proposta da pesquisa } \\
\text { - Acordos iniciais para a formação de um grupo de estudos }\end{array}$ \\
\hline $2^{\circ}$ momento & $\begin{array}{l}\text { - Observação participante na sala de aula } \\
\text { - Aplicação de questionário }\end{array}$ \\
\hline $3^{\circ}$ momento & $\begin{array}{l}\text { - } 13 \text { encontros de formação continuada em serviço - temática: ensino } \\
\text { de ciências tendo como estratégia o uso de histórias em quadrinhos } \\
\text { (momentos gravados em áudio e transcritos posteriormente) } \\
\text { - encontros realizados na escola } \\
\text { - Escrita de um portfólio pelas professoras ao final de cada } \\
\text { encontro }\end{array}$ \\
\hline $4^{\circ}$ momento & $\begin{array}{l}\text { - Elaboração de sessões de leitura } \\
\text { - Utilização das sessões de leitura em sala de aula } \\
\text { - Autoscopia } \\
\text { - Entrevista individual }\end{array}$ \\
\hline
\end{tabular}

Fonte: Quadro elaborado pelos autores para fins deste estudo.

Assim sendo, quando utilizamos essa estratégia, que abarca vários métodos e técnicas, estes não podem ser delineados antes de se entrar no campo investigativo, pois o trabalho se delineia na medida em que as ações acontecem. Assim, os quatro momentos distintos foram se delineando no processo investigativo, o que corrobora a ideia de pesquisa-ação. Uma definição bastante difundida deste tipo de pesquisa é o elaborado por Thiollent (1998, p.14), quando afirma que

[...] a pesquisa-ação é um tipo de pesquisa social com base empírica que é concebida e realizada com estreita associação com uma ação ou a resolução de um problema coletivo para e no qual os pesquisadores e os participantes estão envolvidos de modo cooperativo ou participativo.

Consideramos que uma pesquisa só pode ser chamada de pesquisa-ação se houver uma participação efetiva de todos os envolvidos no processo, a fim de que atuem como autores dos resultados, para que haja uma transformação mútua. Nesse contexto, o pesquisador avalia os problemas da situação real, as ações que se desencadeiam para resolver a problemática, visando ao crescimento de todos. E a nossa escolha por este tipo de pesquisa se dá também porque a pesquisaação é percebida como uma estratégia de formação continuada privilegiada, pois favorece uma emancipação do grupo que participa da investigação. 
Para que haja uma melhor compreensão do processo investigativo, detalharemos o $4^{\circ}$ momento, que é o alvo da discussão aqui tecida. Elaboramos coletivamente sessões de leitura com HQs selecionadas para as aulas de ciências. No momento da leitura dos quadrinhos, adotamos como princípio metodológico a experiência da leitura por andaime (scaffolding), defendida por Graves e Graves (1995), que se trata de um processo que permite ao aprendiz resolver um problema levando adiante uma tarefa ou atingir uma meta que poderia estar além de seus esforços não assistidos. Em seguida, as educadoras usaram os quadrinhos em suas aulas, atividades estas que foram gravadas em vídeo e depois assistidas pelas docentes, utilizando como estratégia a autoscopia (Leite; Colombo, 2006), que é um procedimento no qual o sujeito tem o seu comportamento videogravado em um determinado ambiente e, posteriormente, é colocado em uma situação para observar esse material gravado, editado ou não, para que emita comentários sobre o mesmo, por solicitação do pesquisador e em função dos objetivos da pesquisa. Tal procedimento estimulou as educadoras a repensarem suas práticas, como também possibilitou a evocação das memórias, propiciando um momento ímpar de autoavaliação, gerando comentários pertinentes sobre a prática e os aprendizados decorrentes do processo de formação continuada em serviço.

Ao final da experiência de utilização dos quadrinhos, as professoras foram entrevistadas individualmente, o que, segundo Gaskell (2002), possibilita-nos ter um contato mais profundo com os sujeitos e nos proporcionam momentos de interação muito ricos. As mesmas teceram seus comentários acerca do uso dos quadrinhos nas aulas de ciências naturais, tanto as potencialidades quanto os obstáculos que se apresentaram.

No tocante à pesquisa-ação, esta se justifica por ser uma perspectiva efetiva que, a partir do próprio docente, possibilita-o encontrar respostas aos problemas do ensino, preenchendo uma lacuna existente entre a teoria e a prática, que permite aos professores desenvolverem suas habilidades nas tomadas de decisões. Segundo Imbernón (2009), um dos elementos mais importantes que fundamentam a pesquisa-ação é que a pesquisa seja relevante para a realidade educativa do professor, ao permitir a detecção e resolução de problemas, o que favorece o crescimento de todos os sujeitos envolvidos no processo investigativo, possibilitando vez e voz aos participantes, ao propiciar subsídios para que percebam a dinâmica do seu trabalho. Por haver interação de grande eficácia, promove-se 0 desenvolvimento das relações interpessoais.

\section{Descrevendo os encontros e a protagonista}

A educadora que será focalizada neste artigo será chamada de Arcturus (referência à estrela mais brilhante da constelação de Boieiros), para que tenha 
sua identidade preservada. A docente lecionava na turma do $2^{\circ}$ ano (no ano de 2010) do ensino fundamental, tinha 42 anos, dos quais 25 dedicados à docência. Cursou o magistério no ensino médio e é formada em pedagogia. Segundo dados construídos através do questionário, evidenciou-se que a docente nunca havia participado de uma formação continuada, como também não havia trabalhado com histórias em quadrinhos na sala de aula, mas considera que uma formação que faça uso das histórias em quadrinhos é relevante, por perceber que esse material possui boa aceitabilidade por parte das crianças e acredita que contribuirá para a sua ação docente.

A partir da observação, foi percebido que as aulas estavam pautadas única e exclusivamente pelo que era proposto no livro didático laté mesmo os experimentos realizados), mas a educadora tinha consciência de que esse fato era proveniente da limitação de seus conhecimentos da área, o que dificultava a elaboração de aulas mais interessantes, reconhecendo ainda mais a viabilidade da proposta de formação continuada.

Após os encontros de formação continuada, tivemos os momentos para elaborar as sessões de leitura que seriam aplicadas com as crianças - cada sessão dividida em pré-leitura, leitura e pós-leitura da história em quadrinhos selecionada, seguindo a proposta de leitura por andaime (Graves; Graves, 1995) -, que eram elaboradas pela professora responsável pela turma e, em seguida, discutidas no grupo. Para facilitar esse processo, apresentamos em eslaides uma sessão de leitura como modelo para as professoras, para que percebessem a funcionalidade das perguntas para ensinar um conteúdo proposto. Nesse momento é que as especificidades de cada docente começaram a emergir, inclusive as de Arcturus, o que refletiu diretamente na elaboração de suas aulas.

\section{Analisando as aulas de Arcturus}

Arcturus sempre demonstrou ser uma professora comprometida com a sua profissão. Leu todos os textos propostos para a discussão, foi bastante cuidadosa na escrita do portfólio, era pontual e assídua. Só esses aspectos, em si, já nos davam confiança de que o trabalho seria bem sucedido.

Após as discussões tecidas nos encontros, chegou o momento de planejar as sessões de leitura que seriam aplicadas em sala de aula. Foi nesse instante que começamos a perceber alguns obstáculos na concretização da proposta. Como a ideia inicial era de elaborar questões de pré e pós-leitura de cada $H Q$, Arcturus levou as revistinhas para casa, analisou, pensou e chegou à seguinte conclusão: "Não sei fazer perguntas!". Essa frase foi repetida diversas vezes. Porém, observando suas aulas, percebemos que ela sempre fazia questionamentos ao apresentar um texto novo para as crianças. Tentamos incentivá-la a fazer as perguntas, mas fomos 
percebendo que ela se sentia sufocada com a nossa insistência e que precisávamos frear a nossa ansiedade e esperar um pouco, afinal o redimensionamento das propostas faz parte das espirais cíclicas que são geradas em um processo de pesquisa-ação.

Apesar da dificuldade de elaborar perguntas afirmada pela professora, esta demonstrava todo o tempo que queria que a pesquisa tivesse continuidade com rapidez; estava disposta a aprender e a participar efetivamente. Contudo, pela nossa convivência de mais de um ano nos momentos de formação continuada que era realizada no ambiente escolar, podemos considerar que tal pressa em aplicar os quadrinhos na sala de aula, apesar de ser uma atitude de compromisso para com o estudo em questão, também refletia que Arcturus estava arraigada em uma perspectiva técnica de formação, que incidia diretamente no modelo de treinamento com o qual executava as suas funções.

Percebemos que Arcturus encontrava-se envolvida em uma série de atividades burocráticas escolares que deveria executar, como relatórios, listas de frequência, elaboração de vários e minuciosos planejamentos didáticos individuais o que, segundo Contreras (2002, p. 32), repercute no processo de “[...] desqualificação intelectual, de degradação das habilidades e competências profissionais dos docentes, reduzindo seu trabalho à diária sobrevivência de dar conta de todas as tarefas que deverão realizar". Reconhecendo essa dificuldade, participamos efetivamente na construção das aulas. Na primeira delas, Arcturus preferiu fazer uma introdução sobre a natureza da ciência, para, em uma segunda aula, iniciar as atividades com histórias em quadrinhos. Nessa primeira aula, a professora apresentou alguns instrumentos simples de observação (lupa, binóculo etc.), para falar depois sobre o telescópio, que estava inserido nos quadrinhos de que faria uso.

Arcturus realizou as duas aulas na mesma semana. Na primeira aula estavam presentes 15 dos 16 alunos. Arcturus prosseguiu olhando seguidas vezes 0 planejamento, a fim de não fugir da proposta. Ao questionar aos alunos o que era ciência, foi registrando no quadro cada resposta, e, no final, expôs o seu ponto de vista, como vemos no trecho da transcrição abaixo:

Preste atenção: a ciência, ela vai se modificando. Por exemplo, uma coisa que foi descoberta, que era verdade hoje, daqui a um tempo, quando vocês crescerem, pode ser que aquilo que foi descoberto hoje não seja mais verdade, porque outras pessoas estudaram e chegaram à conclusão de que aquilo não serve mais. Aí eles vão pesquisar e vão fazer uma nova descoberta.

As aulas que aqui serão apresentadas foram realizadas no início da pesquisa, fase na qual a professora ainda demonstrava muitas dúvidas sobre o difícil conceito de ciência e buscava uma definição fechada para esta. Observando a fala de Arcturus, percebemos a sua visão epistemológica da ciência que reconhece o 
caráter construtivo e não definitivo do conhecimento. A palavra "verdade" também faz parte do seu discurso, característica essa da ciência difícil de ser desvinculada da fala da docente. Mas, paradoxalmente, afirma que a verdade não irá servir mais, apontando para uma visão de uma "ciência descartável".

Existem diversas concepções equivocadas sobre a natureza da ciência, como a de que a ciência é o reflexo da realidade, que a verdade científica é absoluta, que existe "o" método científico, entre outras. Vários trabalhos já foram escritos visando superar o modelo pautado no método da indução (Chalmers, 1999; Lopes, 1996). Debates no campo da filosofia das ciências buscam redimensionar o olhar do educador sobre o método científico tradicional, como também da visão do cientista como "promotor" de uma esperada melhoria na sociedade. Contudo, tal pensamento equivocado é percebido quando Arcturus explica para os alunos a função do cientista:

[...] cientista é aquela pessoa que estuda, que pesquisa, que descobre e aí ele vai... Por isso que a ciência vai mudando, porque as coisas vão mudando e hoje eles descobrem um fato. Daqui a alguns anos, eles continuam estudando, estudando, estudando, e eles vão descobrir que aquilo que eles tinham descoberto há três anos atrás não serve mais pra hoje. Aí eles vão estudando pra descobrir[...] Viu A4?, outras coisas, outras técnicas pra melhorar a qualidade da nossa vida.

Fica evidenciada, no discurso da professora, a visão da ciência como promotora de uma qualidade de vida, concepção indevida, pois, como afirma Leodoro (2009, p. 215): “não se pode [...] postular uma neutralidade da ciência frente à técnica, pois o pensamento científico traria em si um caráter instrumentalista". Tal aspecto evidenciado no discurso da professora demonstra o pouco conhecimento das relações estabelecidas entre ciência, tecnologia, sociedade e ambiente. Segundo Arcturus, as novas pesquisas são geradas pelas novas demandas (quando utiliza a expressão "estudando, estudando, estudando"), comovia capaz de gerar novos conhecimentos, que descartam os anteriores, o que contribui para uma visão deturpada do cientista, como alguém que cria algo novo de tempos em tempos, desconsiderando os saberes historicamente elaborados.

Após trabalhar com os alunos o conceito de ciência/cientista, a professora apresenta os instrumentos para se fazer observação que havia levado à sala de aula. A palavra "descoberta" é recorrente na fala da professora.

A aula seguinte foi no auditório e, como relata a própria professora, foi a primeira vez que estava lecionando fazendo uso de uma apresentação em power point e com HQs nas aulas de Ciências.

A história escolhida foi “Astronauta em: O Colecionador de Estrelas”. Nessa HQ, 0 personagem Astronauta apresenta para uma criança, Aldebaran Antares Júnior, vários tipos de estrelas, da forma lúdica que é característica da Turma da Mônica. Antes disso, há uma rápida introdução sobre a importância das estrelas para os diferentes povos, o que pode ser observado abaixo: 
Quadro 2 - Síntese da história analisada

\begin{tabular}{|c|c|c|}
\hline \multicolumn{3}{|c|}{ História analisada } \\
\hline Título & Ideia central - síntese & Conteúdo científico \\
\hline $\begin{array}{l}\text { Astronauta em: } 0 \\
\text { Colecionadorde Estrelas } \\
\text { parte I }\end{array}$ & $\begin{array}{l}\text { Aldebaran Antares Júnior está no } \\
\text { observatório astronômico admirando } \\
\text { o céu. Ao passar uma estrela cadente, } \\
\text { ele faz um pedido: gostaria de ver } \\
\text { as estrelas mais de perto! Pedido } \\
\text { realizado, agora ele pode conhecer } \\
\text { uma série de estrelas diferentes, com } \\
\text { as devidas explicações do Astronauta. } \\
\text { Mas, no meio do céu, tem alguém que } \\
\text { está colecionado estrelas. Como será } \\
\text { que ele está fazendo isso? }\end{array}$ & $\begin{array}{l}\text { História da Ciência: a } \\
\text { importância das estrelas para a } \\
\text { humanidade.Etnoastronomia. } \\
\text { Conceito de estrela.Tecnologia } \\
\text { dos observatórios astronômicos. } \\
\text { Tipos de estrelas }\end{array}$ \\
\hline
\end{tabular}

Fonte: Quadro elaborado pelos autores para fins deste estudo.

A proposta inicial era que a professora expusesse a $\mathrm{HQ}$ e realizasse os seguintes questionamentos de pré-leitura:

Quadro 3: Questões de pré-leitura - 0 Colecionador de Estrelas

\section{Questões de pré-leitura:}

- Hoje vamos ler uma história do personagem Astronauta. Onde vocês acham que ela vai acontecer?

- 0 título da história é: "O Colecionador de Estrelas". Sobre o que vocês acham que vai tratar?

- A primeira página da $\mathrm{HQ}$ apresenta o papel atribuído às estrelas no decorrer da história da humanidade. Na sua opinião, para que serve a história da ciência?

- 0 que vocês sabem sobre as estrelas?

- Como vocês acham que esses conhecimentos chegaram até nós? Será que sempre pensavam nas estrelas como pensamos hoje?

- O nome de um dos personagens da história é "Aldebaran Antares". Será que existe alguma razão especial para ele ter esse nome?

Fonte: Quadro de questões elaboradas para fins deste estudo, adaptadas de Carvalho, 2007.

Arcturus ouviu todas as respostas aos questionamentos, mas não interagiu nem retomou as concepções espontâneas dos educandos no momento de pós-leitura. A docente observou atentamente o planejamento estabelecido, seguindo-o passo a passo, sem negligenciar nenhum aspecto ali presente. Sem esquecer-se dos 
objetivos da aula, que eram os de introduzir o conceito de Astronomia, apresentar diversos tipos de estrelas e refletir sobre a importância dos instrumentos para a observação científica, Arcturus foi explicando para os alunos o que ela queria obter de cada questão. Os trechos sublinhados, a seguir, são trechos da HQ estudada, que são complementados pela fala da professora:

Desde a Pré-História, desde muito tempo, o homem já era fascinado pelas estrelas, porque como o homem não tinha muito conhecimento, era uma coisa assim, de difícil entendimento, ele queria descobrir - viu, A2? - das estrelas estarem em cima. 'Será que elas vão cair na cabeça da gente? Será que, se chovesse muito, o céu iria desabar?', então, durante muito tempo, há muitos anos atrás, o homem já tinha essa curiosidade, sobre essas coisas que existiam no céu. Então ele começou a pesquisar - viu, A5? para tentar descobrir essas coisas sobre o universo, que quase ninguém sabia do que se tratava.

Nesse trecho, Arcturus expõe para os alunos suas concepções sobre a Astronomia, mas, apesar de ter lido informações sobre o tema proposto, seu discurso ainda está pautado na esfera da opinião, não acrescentando aspectos dessa ciência para a formação dos alunos.

Arcturus começou a ler a $\mathrm{HQ}$ sem olhar para os alunos, mas explicou cada trecho. Ela sentiu o desejo de abordar logo o tema, mas expressou dificuldade de tecer uma discussão com os alunos, como podemos perceber no momento em que faz a $3^{a}$ pergunta: “A primeira página da $H Q$ apresenta o papel atribuído às estrelas no decorrer da história da humanidade. Na sua opinião, para que serve a história da ciência?". Arcturus complementa a pergunta com "pra que a gente deve aprender Ciências?", questão que, na verdade, não tem nenhuma relação com a questão anterior e leva as crianças a fugirem do foco da discussão. As crianças começam a responder e, a cada resposta, Arcturus repete o que foi dito, como se estivesse confirmando a fala de cada uma:

A3 - Pra aprender.

Arcturus - Pra aprender, muito bem. Pra você, A1?

A1 - Pra aprender a ler.

Arcturus - Certo. E pra você, A7?

A7 - Pra aprender tudo sobre Ciências.

Arcturus - Muito bem. E pra você, A2?

A2 - Pra aprender sobre o céu.

Arcturus - Pra aprender sobre o céu, isso aí. E você, A6?

A6 - Aprender sobre o sol!

Arcturus - Aprender sobre o sol, certo. E você, A4?

A4 - É pra aprender sobre a lua!

Arcturus - Aprender sobre a lua, muito bem. E você, A3? 
A3 - Pra aprender muitas coisas!

Arcturus - Certo. E pra você, A5?

A5 - É pra aprender um monte de coisa, sobre o espaço, pra olhar no telescópio!

Arcturus - Muito bem!

0 ato de confirmar cada uma das questões não seria tão problemático no momento da pré-leitura, caso as concepções fossem retomadas no momento da pós- leitura, mas isso não ocorreu. Freire (1996, p. 95) aponta que “[...] como professor, não me é possível ajudar o educando a superar a sua ignorância se não supero permanentemente a minha. Não posso ensinar o que não sei".

Em outro momento, ainda na pré-leitura, Arcturus questiona:

Arcturus - 0 que são as estrelas? Pra que servem as estrelas?

A5 - Deus fez as estrelas pra iluminar a noite junto com a lua!

Arcturus - Pra iluminar a noite junto com a lua... certo. Quem mais?

A1 - Pro céu ficar bonito!

Arcturus - Pro céu ficar bonito, muito bem! Quem mais?

A7 - Pra enfeitar o céu!

A12 - Pra iluminar a noite, porque a lua é fraca!

Arcturus - Pra iluminar a noite, porque a lua é fraca, muito bem. E você?

A13 - Pra ajudar a lua a iluminar a Terra!

Arcturus - Pra ajudar a lua a iluminar a Terra, não é assim.

A3 - Tem água na lua!

A14 - Tem, mas é água congelada!

Arcturus - Tem água na lua? E a água é congelada? E a gente sobreviveria com água congelada? Vamos fazer como os cientistas, vamos pesquisar!

Apesar de os alunos apresentarem concepções pouco elaboradas sobre o que são e/ou para que servem as estrelas, levantam algumas questões que são interessantes, e suscitariam uma boa discussão: “a lua é fraca”, “tem água na lua!”, “Tem, mas é água congelada", mas que não são exploradas pela professora, nem no momento da aula nem em outra ocasião, de acordo com relatos da mesma.

Segundo Langhi e Nardi (2009):

Esta situação de despreparo do docente e de divulgação de erros conceituais pelas mais diversas fontes pode proporcionar, durante o processo de ensino e aprendizagem, 0 surgimento ou reforço de concepções alternativas lque os próprios professores podem possuir desde os primórdios de sua trajetória de vida, enquanto crianças carregadas de crenças e mitos) sobre fenômenos astronômicos, acarretando sérios erros conceituais sobre Astronomia durante as aulas que devem contemplar conteúdos de Ciências. (Langhi; Nardi, 2009, p. 239) 
Além das limitações de ordem conceitual que são percebidas nos momentos de intervenção nas falas dos alunos, Arcturus também não tece diálogos com as crianças, mas sim uma "ilusão interrogativa" (Weissmann, 1998), no qual o jogo de perguntas e repostas não acontece de forma dialógica, mas é apenas o professor lançando perguntas e respostas como um jogo de adivinhação. Dessa forma, o aluno não hipotetiza, não se torna epistemologicamente curioso (Freire, 1996), mas apenas apresenta suas opiniões que são acatadas, não discutidas.

As aulas citadas serviram para que nos questionássemos: como uma formação continuada que faz uso de histórias em quadrinhos nas aulas de Ciências naturais pode contribuir para um olhar mais crítico e reflexivo sobre a prática? Esse foi o ponto crucial para a compreensão da validade didática da estratégia que estávamos aplicando. Porém, desde o princípio tivemos clareza sobre a limitação da proposta e o papel crucial do professor para que esta fosse bem sucedida. Nossas angústias também residiam no fato de percebermos que, mesmo apesar de termos discutido aspectos referentes tanto à aplicação quanto ao conteúdo conceitual proposto, não percebemos grandes avanços no tocante às aulas desenvolvidas. Agora, nossa preocupação ia além da aplicação da $\mathrm{HQ}$, estava ligada à relevância da formação continuada. Teria esta formação contribuído para uma nova visão da professora ou seria apenas mais uma função burocrática que deveria executar? Tais inquietações foram amenizadas no momento do feedback final escrito, no qual Arcturus assim descreve nossos momentos de formação continuada:

\section{Quadro 4 - Avaliação dos encontros realizada por Arcturus}

Os encontros de formação continuada foram muito proveitosos para a minha prática pedagógica.

Através desses momentos pude não só aprender conhecimentos novos, mas rever a minha postura em relação à minha prática pedagógica.

Nesse período houve bastante discussão sobre o nosso fazer pedagógico, onde cada participante podia explorar sua opinião e depois juntos formaríamos o conceito.

Acredito que como educadores e formadores de opiniões temos sempre que estar não só buscando novos saberes, mas também rever a nossa prática para que assim possa haver um fazer pedagógico com qualidade.

Fonte: portfólio dos sujeitos da pesquisa.

Apesar de a professora haver sinalizado que a formação contribuiu para a sua prática pedagógica, pelo que foi visto, refletimos: como se efetivou sua prática? Isso se refletiu em mudanças de qualidade? A partir do que foi escrito por Arcturus, refletimos no que Franco (2008) discute: 
Incorporar a reflexão à prática coletiva é um processo muito lento, progressivo e que deve ir fluindo gradativamente. Esse processo que permeia toda a pesquisa-ação é muito demorado, exige o tempo de cada um. Há que se dar um tempo para amadurecer novos olhares, sentimentos de dissonâncias, aberturas e defesas ao novo. (Franco, 2008, p. 119-120)

Sabemos que cada um tem o tempo de "maturar" determinadas mudanças em sua prática docente, e, através das sessões de autoscopia (filmagem e discussão), como também na entrevista individual, na qual a nossa percepção foi exposta para a professora, pudemos tratar das questões que consideramos relevantes, no intuito de apresentar as nossas inquietações e, acima de tudo, ouvir o posicionamento desta.

Quanto a questionamos sobre as dificuldades para ensinar Ciências com quadrinhos, ela alega:

Eu tive dificuldade tanto com o espaço (o auditório), que eles não estavam acostumados - eu achei que eles ficaram perdidos - e também com a história, e, como eu não tenho o hábito de contar HQs pra eles, eu senti muita dificuldade.

Na fala de Arcturus não percebemos nenhuma relação com a dificuldade concernente ao conteúdo conceitual proposto, o que nos levou a fazer uma pergunta específica sobre esse aspecto, da qual obtivemos a seguinte resposta:

Eu acho que foi a questão do assunto. Se fosse um assunto assim, mais fácil, eu acho que eu não ia sentir dificuldade de explicar desse jeito que eu tô fazendo. Eu acho que, se fosse um assunto mais fácil, assim, mais corriqueiro deles, eu ia contar direto, mas como esse assunto falava de estrelas, não sei o quê, e palavras, assim, que eles nunca ouviram falar, aí eu senti a necessidade de ir explicando pra eles, pra eles não perderem o raciocínio.

[...]

Eu não tenho o conhecimento daquela história do Colecionador de Estrelas, daquele monte de coisas, foi o que eu achei mais difícil, pela falta de conhecimento minha mesmo, mas mesmo assim eu acho que eu escapei com vida. (risos)

MED - E você estudou pra dar essa aula?

Arcturus - Não, estudar, estudar não! Eu vi algumas coisas na internet e vi uns papéis que você me deu, eu dei uma olhada, mas estudar, estudar, estudar, não.

Sabemos que o ensino está intimamente ligado à pesquisa e que o professor deve estar "repousado neste saber" (Freire, 1996). Sabemos também que o conhecimento do conteúdo não é o único aspecto que deve ser observado em sala de aula, porém, temos clareza que "[...] um dos principais obstáculos no momento de querer ensinar é a falta de domínio e de atualização dos professores, no que se refere aos conteúdos 
escolares" (Weissmann, 1998, p.32). Assim sendo, consideramos que Arcturus deveria ter se preparado mais para a execução dessa aula.

Contudo, apesar das limitações percebidas em suas aulas, afirmou que aspectos mencionados nestas foram lembrados pelas crianças em um momento posterior, na ocasião em que os alunos foram visitar um observatório astronômico.

Dessa forma, consideramos que a aula teve a sua contribuição, até pela ludicidade dos quadrinhos. Consideramos as $\mathrm{HQ}$ material lúdico, pois propiciam um jogo de linguagem e um jogo com personagens; têm um sistema linguístico particular, oferecendo dessa forma ao jovem leitor um momento de profunda identificação com as vivências dos personagens presentes na narrativa. Umberto Eco ratifica essa ideia da leitura ficcional - da qual as HQ fazem parte - como jogo, ao afirmar que:

A ficção tem a mesma função dos jogos. Brincando, as crianças aprendem a viver, porque simulam situações em que poderão se encontrar como adultos. E é por meio da ficção que nós, adultos, exercitamos a nossa capacidade de estruturar nossa experiência passada e presente. (Eco, 1994, p. 137)

As $H Q$ possuem a relação semiótica do icônico e do verbal, o que favorece a compreensão e identificação da criança com o enredo proposto. Tal característica lúdica pode ser um dos motivos pelos quais os alunos conseguem retomar alguns conceitos científicos que foram trabalhados através das histórias da Turma da Mônica, ainda que só percebido meses depois, conforme afirma a docente:

Eu acho que, mesmo com os entraves que tiveram, eu creio que tanto foi boa pra eles, pro aprendizado deles; eles abriram mais a cabeça com relação às questões científicas. É tanto que, quando eles voltaram do planetário, eles voltaram cheios de ideias e de coisas que eles lembraram que viram quando estudaram isso, e eu vejo como uma experiência muito boa.

Esses são alguns aspectos positivos que só temos a possibilidade de perceber nos momentos de feedback, na ocasião de interlocução com a docente após as sessões de autoscopia, pois não são alcançados de imediato.

Quando a questionamos sobre a formação de uma forma geral, Arcturus assim se posicionou:

Eu achava sempre suas interações muito boas, que uma das coisas que você tem de bom é que, por exemplo, eu sei que eu sou chata muitas vezes: quando eu não consigo fazer, eu paro ali, e você em nenhum momento perdeu a paciência comigo, porque, se fosse eu, mandava você ir embora (risos). Então, assim, você persistiu, sabe? E eu achei isso muito bom, porque, no seu lugar, eu não teria essa coragem, essa paciência, não. Você chegava e dizia 'não, Arcturus, o que tá acontecendo? Não, eu ajudo você! Mas você não já faz isso em sala de aula?'. Mas é que eu não tava conseguindo escrever e, 
sabe, eu gostei demais, e essa proposta é muito boa, mesmo eu não tendo tido costume de ler na minha infância, na minha adolescência, $H Q$. $H Q$, pra mim, é de quatro anos pra cá, mas, como eu disse a você, pelo fato de eu ter consciência que é um recurso muito bom e que, além de ser um recurso bom para o professor utilizar, o aluno é muito receptivo em relação a ele, então eu também tenho me esforçado pra entrar na onda do aluno, pra gostar e ser uma coisa boa pra eles e pra mim também.

Como percebemos pelo discurso acima, Arcturus não apresentou muita desenvoltura na aula com os quadrinhos, tanto por não possuir muitos conhecimentos sobre o conteúdo proposto, como por não ter muita afinidade com a estratégia metodológica adotada, mas, fazendo uso do seu próprio discurso, está tentando "entrar na onda do aluno", por estar, de certa forma, reconhecendo os aspectos positivos dessa proposta.

Sobre a realização do trabalho em grupo, Arcturus afirma:

[...] Eu sempre acreditei muito no trabalho coletivo [...], porque eu acho que você com o outro..., por exemplo, eu leio o texto, aí você lê o mesmo texto, porque você tem um olhar sobre uma coisa que eu não percebi, como também eu posso ter um olhar sobre uma coisa que você nem se deu conta. [...] quando a gente trabalha junto, existe muito mais a possibilidade da gente crescer, crescer mesmo como pessoa, e isso vai, com certeza, refletir na nossa prática, até pra a gente poder dizer pras crianças, porque muitas delas têm dificuldade de trabalhar em grupo [...] eu penso que, quando a gente tá junto, existe muito mais possibilidade de aprendizado do que você sentar e pensar nas coisas sozinho.

Um aspecto pertinente para Arcturus foi exatamente uma de nossas defesas para se desenvolver uma pesquisa-ação: o trabalho coletivo. Apesar das limitações em outros aspectos, como a apropriação do conteúdo conceitual e a desenvoltura na utilização da $H Q$ no contexto da sala de aula, as dimensões que as espirais cíclicas desenvolvem são ilimitadas e extremamente pessoais. Isso também serviu para que pudéssemos refletir em nosso papel como pesquisadores que lidam com sujeitos: não podemos - e nem devemos - tentar encaixar os participantes de uma pesquisa em moldes estabelecidos a priori, pois esta também é uma ação negativa que reflete o modelo formativo pautado na racionalidade técnica, que tanto criticamos.

\section{Considerações finais}

Apesar de termos percebido algumas limitações na ação pedagógica de Arcturus, o objetivo deste estudo não é apenas evidenciar tais limitações, mas sinalizar as possibilidades. Sabemos que não é fácil abrir a sala de aula e expor as 
suas dificuldades. Mais difícil ainda é quando essa exposição está registrada em vídeo, que pode ser revista de tempos em tempos. Assim sendo, para que nossa proposta não se apresente como uma lista das limitações que nos deparamos no ambiente escolar é que elaboramos dois quadros-síntese: o primeiro, mapeando os obstáculos. E o segundo, as possibilidades que percebemos na intervenção de Arcturus:

Figura 2: Obstáculos/Limitações apresentados nas aulas de Arcturus.

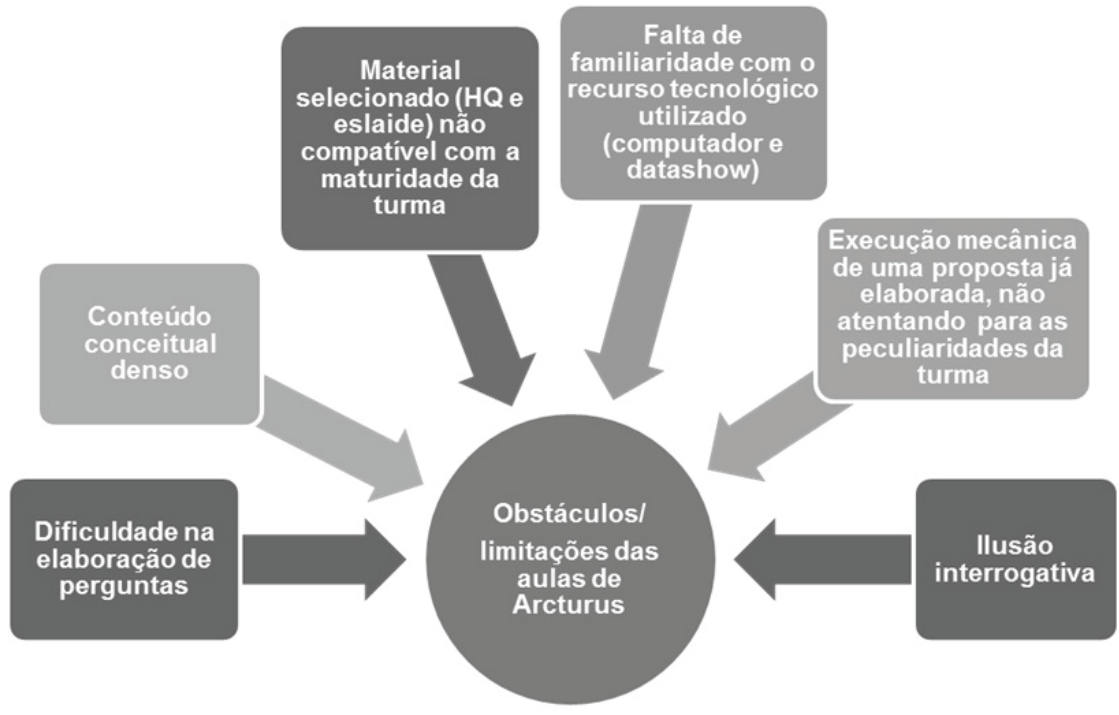

Fonte: para fins deste estudo.

Figura 3: Aspectos positivos da ação didática de Arcturus.

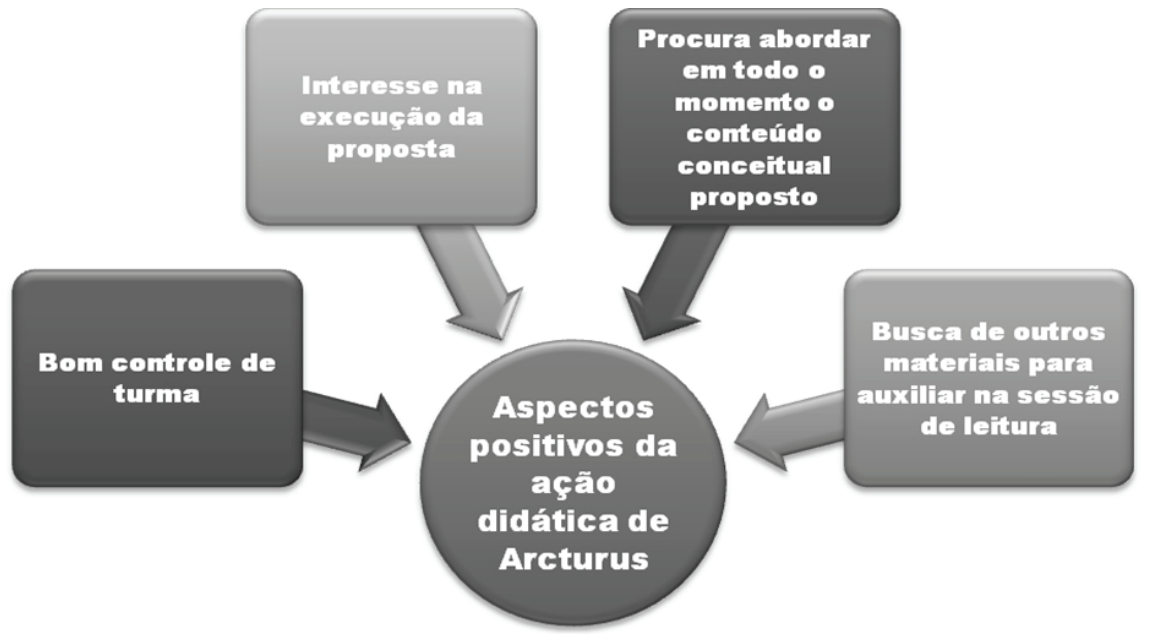


Nesse sentido, como já discutimos anteriormente, é inconteste a relevância de uma formação coletiva, dentro do espaço escolar, como uma possibilidade de consolidar a pesquisa e a reflexão entre os docentes, considerando que a pesquisa e a reflexão possibilitam a emancipação do trabalho docente.

Temos clareza do subsídio da formação continuada no processo de ação reflexiva por parte das docentes, como já discutimos no início deste artigo. E uma das formas pelas quais contribuímos para a formação reflexiva certamente foi a abertura ao diálogo, por considerarmos a dialogicidade como uma via de superação da educação bancária e da hierarquização do conhecimento. Nessa perspectiva, são valorizados os conhecimentos prévios dos envolvidos, ao passo que os erros que vão se delineando são um novo passo para a aprendizagem.

Como já citamos, há diferentes concepções sobre as práticas reflexivas, mas todas estas repercutem em um olhar mais significativo para o trabalho do professor, rompendo com a racionalidade técnica e valorizando os saberes docentes, em suas diversas instâncias, oportunizando vez e voz aos professores, em espaços de formação continuada que promovam esse olhar reflexivo no próprio ambiente de trabalho.

As dificuldades que foram percebidas na ação didática da professora estão ligadas à necessidade de se ter uma maior familiaridade com os quadrinhos e com a forma de levá-los para a sala de aula, nesse caso, fazendo uso de aparatos tecnológicos, como scanner, computador e datashow. Na indisponibilidade de uma revistinha para cada aluno (que consideramos ser o ideal), o professor deve ter domínio sobre o uso dos instrumentos que levará para o ambiente escolar.

A falta de conhecimento do conteúdo conceitual também prejudicou o bom aproveitamento das HQs em sala de aula, pois é necessário que o professor esteja repousado no saber que vai ensinar. Existem lacunas, sim, de ordem conceitual (referentes aos conteúdos específicos das Ciências naturais), pois a formação inicial não contempla - e nem poderia contemplar - a quantidade de conteúdos conceituais necessários ao exercício da docência. Assim, a formação continuada em serviço pode favorecer esse aspecto, visto que é um momento em que se pode discutir sobre questões conceituais, nos quais o professor deve se sentir à vontade para expressar as suas inquietações, estando amparado por outros profissionais que estão na mesma dinâmica de trabalho.

Apesar de não termos percebido um avanço significativo da superação do senso comum por parte da professora no decorrer do nosso estudo, o que não se pode é pensar que nenhum percurso foi trilhado. Na caminhada pelos (des)caminhos da docência, a professora poderá aprimorar os seus conhecimentos e expandir seus horizontes, afinal, já reconhece suas limitações, o que é um primeiro passo para a superação destas.

Temos clareza das dificuldades que se delinearam para a execução da proposta para Arcturus. Reconhecemos que, como proferiu Freire (1996), ensinar exige o reconhecimento de ser condicionado, e isso não é fácil. Arcturus segue com 
esse modelo da racionalidade técnica há muitos anos e não seria uma formação de curto prazo que a faria mudar drasticamente essa realidade. Porém, a sua contribuição no tocante à percepção sobre o trabalho coletivo foi imprescindível para que continuássemos acreditando na proposta inicial, que o esforço vale a pena. Como disse Freire (1996, p. 52): “Sei que as coisas podem até piorar, mas sei também que é possível intervir para melhorá-las".

Temos consciência que a semente foi lançada. E que novas investigações poderão ser suscitadas a partir dessa prática.

\section{Referências}

ALARCÃO, Isabel (org). Escola reflexiva e nova racionalidade. Porto Alegre: Artmed, 2001.

AMARILHA, Marly (Coord.). 0 ensino da literatura infantil da $1^{a}$ à $5^{a}$ séries do $1^{\circ} \mathrm{grau}$ nas escolas da rede estadual do Rio Grande do Norte: Relatório final. Natal: CNPq/ UFRN/Departamento de Educação, 1994.

CARVALHO, Letícia dos Santos. Ensinar ciências com quadrinhos: que história é essa? 105f. 2007. Monografia (Graduação em Pedagogia) - Universidade Federal do Rio Grande do Norte, Natal, 2007.

CHALMERS, Alan. A fabricação da Ciência. Tradução de Beatriz Sidou. São Paulo: UNESP, 1999.

CONTRERAS, José Domingo. La investigacíon em la acción. Tema del Mês. Cuadernos de Pedagogia, 224, p. 7-19, abril, 1994.

ECO, Umberto. Seis passeios pelos bosques da ficção; Tradução de Hildegard Feist. São Paulo: Companhia das letras, 1994

FRANCO, Maria Amélia Santoro. Pesquisa-ação e prática docente: articulações possíveis. In: PIMENTA, Selma Garrido; FRANCO, Maria Amélia Santoro. Pesquisa em educação: Possibilidades investigativas e formativas da pesquisa-ação. São Paulo: Edições Loyola, 2008, p. 103-138, v.1.

FREIRE, Paulo. Pedagogia da autonomia: Saberes necessários à prática educativa. São Paulo: Paz e Terra, 1996.

GASKELL, George. Entrevistas individuais e grupais In: BAUER, Martin; GASKELL, George. Pesquisa qualitativa com texto, imagem e som: um manual prático. Tradução de Pedrinho A. Guareschi. 5. ed. Petrópolis: Vozes, 2002, p. 45-79.

GIL-PÉREZ, Daniel; CARVALHO, Anna Maria Pessoa de. Formação de professores de Ciências. Tradução de Sandra Valenzuela. São Paulo: Cortez, 2006.

GIROUX, Henry. Os professores como intelectuais: Rumo a uma pedagogia crítica da aprendizagem. Porto Alegre: Artmed, 1990.

GONÇALVEZ, Rosilena; MACHADO, Deusana Maria. Cómics: investigación de conceptos y de términos paleontológicos, y uso como recurso didáctico en la 
educación primaria. Enseñanza de las Ciencias, v. 23, n. 2, p. 263-274, 2005.

GRAVES, Michael; GRAVES, Bonnie. The scaffolding reading experience: a flexible framework for helping students get the most out of text. In: Reading. April, 1995. (Trad. Marly Amarilha, para estudo exclusivo do grupo de pesquisa NEPELC UFRN).

HIGUCHI, Kasuko Kojima. Super- Homem, Mônica e cia. In: CITELLI, Adilson; CHIAPPINI, Ligia (coord). Aprender e ensinar com textos não escolares. São Paulo: Cortez, 1997, p. 125-154, v. 3.

IMBERNÓN, Francisco. Formação docente profissional: formar-se para a mudança e a incerteza. 7. ed. São Paulo: Corte, 2009.

KAMEL, Claudia. Ciências e quadrinhos: explorando as potencialidades das histórias como materiais instrucionais. 2006. 113f. Dissertação (Mestrado em Ensino em Biociências e Saúde), Instituto Oswaldo Cruz - Fiocruz, Rio de Janeiro: 2006.

LANGHI, Rodolfo; NARDI, Roberto. Construção de saberes disciplinares em Astronomia durante trajetórias formativas de professores dos anos iniciais do ensino fundamental. In: BASTOS, Fernando; NARDI, Roberto (orgs.). Formação de professores e práticas pedagógicas no ensino de Ciências: contribuições da pesquisa na área. São Paulo: Escrituras editora, 2008, p.235-258.

LEITE, Sérgio Antonio da Silva; COLOMBO, Fabiana Aurora. A voz do sujeito como fonte primária na pesquisa qualitativa: a autoscopia e as entrevistas recorrentes. In: PIMENTA, Selma Garrido; GHENDIN, Evandro; FRANCO, Maria Amélia Santoro. Pesquisa em educação: alternativas investigativas com objetos complexos. São Paulo: edições Loyola, 2006

LEODORO, Marcos Pires. Ciência e cultura material: contribuições à educação científica. In: MARTINS, André Ferrer Pinto (org). Física ainda é cultura? São Paulo: Livraria da Física, 2009, p. 211-230.

LOPES, Alice Ribeiro Casimiro. Bachelard: o filósofo da desilusão. Caderno Catarinense de Ensino de Física, v.13. n.3, dez. 1996.

PÉREZ GÓMEZ. Angel. A função e formação do professor/a no ensino para a compreensão: diferentes perspectivas. In: PÉREZ GÓMEZ. Angel; SACRISTÁN. Juan Gimeno. Compreender e transformar o ensino. Tradução de Ernani F. da Fonseca Rosa. 4. ed. Porto Alegre: Artmed, 1998.

PIMENTA, Selma Garrido. Professor reflexivo: construindo uma crítica. In: PIMENTA, Selma Garrido; GHEDIN, Evandro (orgs). Professor reflexivo no Brasil: gênese e crítica de um conceito. 5. ed. São Paulo: Cortez, 2008.

PIZARRO, Mariana Vaitiekunas. Histórias em quadrinhos e o ensino de Ciências nas séries iniciais: estabelecendo relações para o ensino de conteúdos curriculares procedimentais, 2009. 188f. Dissertação (Mestre em Educação para a Ciência) UNESP, Faculdade de Ciências, Bauru, 2009.

ROSA, Maria Inês Petrucci. Investigação e ensino: articulações e possibilidades na formação de professores de Ciências. Ijuí: Unijuí, 2004.

$\mathrm{SCHÖN}$, Donald. Educando o profissional reflexivo: um novo design para o ensino e 
a aprendizagem. Tradução de Roberto Cataldo Costa. Porto Alegre: Artes Médicas Sul, 2000.

SOUSA, Mauricio de. Astronauta em: 0 colecionador de estrelas parte I. In: Mônica. São Paulo: Globo. n. 156, out. 1999.

THIOLLENT, Michel. Metodologia da pesquisa-ação. 8. ed. São Paulo: Cortez, 1998. VERGUEIRO, Waldomiro; RAMOS, Paulo. Os quadrinhos (oficialmente) na escola: dos PCN ao PNBE. In: VERGUEIRO, Waldomiro; RAMOS, Paulo (orgs). Quadrinhos na educação: da rejeição à prática, São Paulo: Contexto, 2009, p.09-43.

WEISSMANN, Hilda. 0 que ensinam os professores quando ensinam ciências naturais e o que dizem querer ensinar. In: WEISSMANN, Hilda (org.). Didática das Ciências naturais: Contribuições e Reflexões. Porto Alegre: Artmed, 1998, p. 3156.

Recebido em fevereiro de 2013

Aprovado em junho de 2013

Letícia dos Santos Carvalho é doutoranda em educação pela Universidade Federal do Rio Grande do Norte, integrante do grupo de pesquisa Ensino de Ciências e Cultura, no Programa de Pós Graduação em Educação da UFRN e participante da linha de Pesquisa Educação Matemática e Ensino de Ciências. Email: lleticia_ carvalhodahotmail.com.

André Ferrer Pinto Martins é doutor em educação pela Universidade de São Paulo (2004), professor associado I da Universidade Federal do Rio Grande do Norte (UFRN), e líder do Grupo de Pesquisa Ensino de Ciências e Cultura. Email: aferrer34dyahoo.com.br. 